\title{
PERKEMBANGAN TEKNOLOGI KOMUNIKASI DALAM MENUNJANG FUNGSI PERIKLANAN DAN PUBLIC RELATION
}

\author{
Nurul Candrasari Masykuri \\ Jurusan Marketing dan Komunikasi, Fakultas Komunikasi dan Multimedia, Universitas Bina Nusantara \\ Jln. Kemanggisan Ilir III No.45, Kemanggisan, Palmerah, Jakarta Barat 11480
}

\begin{abstract}
Society has been flooded by advertised communication atmosphere for every product to be socialized and introduced to the public. However, there are problems arising from the consumer when the product being advertised is felt only one-sided communication, because in an advertised product consumers often encounter some problems in which they cannot consider them to be their choice. That is why at the present time the world of advertising does not seem to be a choice in marketing a product to consumers. Article presents the relationship among advertisement, public relation, and communication technology in five parts, those are age sequences from agriculture to conceptual era and its relation to advertisement and public relation, developing advertisement network and public relation using new technology, difference between advertisement and public relation, and communication technology ethic supporting advertisement and public relation.
\end{abstract}

Keywords: advertisement, public relation, communication technology

\begin{abstract}
ABSTRAK
Masyarakat telah dibanjiri iklan berbagai jenis produk yang dalam perkembangan selanjutnya menimbulkan masalah bagi para konsumen, yaitu ketika produk yang diiklankan dirasakan hanya bersifat komunikasi sepihak. Konsumen sering menemukan produk yang diiklankan belum pasti menjadi pilihan yang tepat sehingga pada masa sekarang dunia periklanan tidak terlalu menjadi sebuah pilihan dalam memasarkan sebuah produk kepada konsumen. Pengenalan merek melalui iklan menjadi hal yang utama karena suatu produk akan langsung dapat menjadi dikenal dan akan menjadi baik di mata para konsumen apabila konsumen belum pernah mendengar tentang produk tersebut. Dalam hal ini peran public relation sebagai komunikator sangat penting, begitu pula keterlibatan teknologi komunikasi sebagai media yang akan ditawarkan. Artikel menggambarkan kolaborasi iklan, public relation, dan teknologi baru dalam empat bagian, yaitu perkembangan zaman pertanian menuju zaman konseptual dan relasi terhadap dunia periklanan serta public relation, membangun jaringan periklanan dan public relation menggunakan teknologi baru, perbedaan periklanan dan public relation, dan etika teknologi komunikasi pendukung perilkanan dan public relation.
\end{abstract}

Kata kunci: iklan, public relation, teknologi komunikasi 


\section{PENDAHULUAN}

Perkembangan teknologi komunikasi dalam menunjang fungsi periklanan dan public relation adalah sebuah seni untuk menggabungkan ketiga hal tersebut dalam mencapai target penjualan sebuah merek. Dalam hal ini tentu saja harus dipahami tentang nilai lebih dan nilai kurang dari masing masing fungsi, yaitu fungsi teknologi komunikasi dalam menunjang fungsi periklanan dan fungsi relationship. Ketiga fungsi memiliki nilai yang dikemas menjadi sesuatu yang indah dan akan ditawarkan kepada para pelanggan dan konsumen.

Seni adalah sebuah kata yang amat berperan dalam mencapai target market karena ketika bicara tentang menawarkan sesuatu, maka berarti menawarkan jasa atau barang untuk kepentingan manusia. Dengan demikian, seni pendekatan tehadap manusia menjadi sangatlah penting. Dalam analisis penjualan terdapat beberapa hal yang perlu diperhatikan, di antaranya mengacu dari tulisan 'Sun Tzu's' strategy of winning sales, sebagai, “ Your purpose ins't just to get orders; It is to win and keep customers. It is to win sales quickly and effortlessly. You want to win in way that leaves you ready for the next sale, not so burnt out that you need a vacation."

Satu hal terpenting dalam dunia bisnis adalah pandai melihat peluang dan mengatasi saingan yang selalu akan dipastikan ada. Kesiapan dalam sebuah rencana adalah sebuah hal yang sangat baik. Akhirnya, segala sesuatu harus dibuat sebuah rencana dengan rinci dan jelas serta memahami nilai lebih dan nilai kurang dari setiap fungsi yang akan bekerja sama, yaitu fungsi teknologi komunikasi, fungsi periklanan, dan fungsi public relation.

\section{METODE PENELITIAN}

Artikel disusun berdasarkan studi pustaka, yaitu menemukan dan meyeleksi beberapa sumber referensi dan knowledge baik tercetak maupun elektronik. Informasi yang terpilih menjadi dasar penyusunan artikel ini.

\section{HASIL DAN PEMBAHASAN}

Peran marketing dalam memperkenalkan sebuah produk kepada konsumen membutuhkan cara pendekatan agar produk menjadi pilihan dan dipakai para konsumen.

Don Peppers dan Martha Rogers memperkenalkan konsep one-to-one marketing. Menurut kedua pakar pemasaran ini, teknologi informasi telah memungkinkan terwujudnya tiga kapabilitas yang sangat penting bagi para pemasar, yaitu kemampuan pengelolaan database pelanggan, interactivity, dan mass customization.

Dunia one-to-one adalah sebuah tampilan yang berbeda dengan dunia mass marketing. Di dunia one-to-one, apa yang sering disebut mass communication, broadcasting, dan one-way communication menjadi tidak relevan. Kemudian akhirnya lebih ke segmented atau biasa disebut oneto-one communication sehingga dunia periklanan yang memiliki kecenderungan sifat one-way menjadi tidak populis.

Sebuah ilustrasi bagaimana dunia public relation menjadi lebih menjanjikan adalah sebagai berikut. Sebuah produk kecantikan yang paling mahal saat ini di antaranya adalah produk Kanebo atau 
Clinique. Harga bedaknya saja bisa sampai ratusan ribu rupiah, bahkan ada yang sampai jutaan untuk produk Kanebo yang asli dari Jepang, namun konsumen produk bagi kelas atas ini tetap setia. Walaupun pihak Kanebo atau Clinique tak pernah mengiklankan besar-besaran, ternyata tetap berjaya. Contoh lain dengan sebuah produk kelas menengah ke bawah adalan bedak Mars keluaran Kimia Farma. Dari zaman dahulu sampai sekarang bedak Mars masih tetap bertahan dan digunakan konsumen secara turun temurun.

Kenyataannya, tanpa ada penjualan produk Kanebo, Clinique, dan bedak Mars tetap memiliki pangsa pasar yang meningkat sehingga timbul sebuah pertanyaan "Mengapa bisa demikian?", “Apakah ini karena iklan?”, dan jawabannya adalah tidak. Pada kenyataannya, sebuah merek yang dikenali konsumen lebih dikarenakan komunikasi yang memiliki sifat peer-to-peer dan bukan topdown: pointcasting bukan juga broadcasting, dan bukan two-way dan juga bukan one-way. Pada akhirnya, dunia pemasaran telah mengalami pergeseran sejak lahirnya sebuah era teknologi informasi seperti internet.

Selanjutnya, dalam tiga puluh tahun yang lalu serangkaian artikel dengan topik Advertising Age dengan judul "The positioning Era Cometh" menjelaskan pergeseran pemasaran yang berorientasi pada periklanan ke pemasaran yang berorientasi kepada public relation (PR). Di sini, public relation memiliki kredibilitas dalam membangun persepsi positf, sedangkan budaya periklanan yang hanya terjalin one-way telah bergeser ke sebuah evolusi alami dalam cara memasarkan sebuah produk.

\section{Perbedaan Periklanan dan Public Relation}

Membicarakan perbedaan antara periklanan dan public relation mengingatkan akan sebuah dongeng klasik tentang "Matahari dan Angin". Mereka berdebat untuk membuktikan siapa di antara mereka yang lebih hebat. Ketika seorang pengembara sedang berjalan, matahari dan angin memutuskan untuk bertanding dengan cara mencoba mengusahakan si pengembara agar segera membuka jaketnya. Segera angin beraksi menyerang dengan menghembuskan angin sekencangkencangnya, namun ternyata dengan hembusan semakin kencang sang pengembara dengan sekuat tenaga semakin menahan jaket sebagai pelindung dari serangan angin kencang. Kemudian, sang matahari ke luar dan sinar pun menyelimuti sang pengembara, tak lama kemudian dia segera membuka jaketnya, dan mathari menjadi pemenang.

Ilustrasi di atas secara sederhana memandang periklanan sebagai angin yang memaksakan. Semakin kuat sebuah iklan, akan semakin kuat pula prospek hendak melawan periklanan tersebut. Dunia periklanan selalu akan memberikan masalah bagaimana cara menampilkan sebuah kesan dan dampak. Periklanan akan menampilkan sisipan khusus foldouts, dan iklan berwarna dengan warnawarni yang memenuhi halaman. Terkadang membuat pesan yang tampak berlebihan dan hampir tak masuk akal seperti baligho yang super raksasa di setiap hampir sudut jalan, dan jump cut dalam iklan televisi dengan menambah jam tayang iklan dalam spot-spot di radio, namun dengan iklan tersebut seakan membuat konsumen semakin mengabaikannya.

Selain hal tersebut, periklanan yang memiliki sifat visual seringkali dalam memakai moto yang dipakai sebagai pemuja Konfusius, yaitu "sebuah gambar memiliki nilai seribu kata”. Akibat dari kepercayaan tersebut, sering dijumpai bahwa tampilan dari sebuah iklan yang hanya berbentuk visual, namun pada kenyataannya tak selalu dapat menggapai konsumen.

Sedangkan esensi mendasar dari public relation adalah kebalikan dari periklanan. Pada hakikatnya, public relation lebih memverbalkan sebuah produk dengan cara personal approach dan dilakukan oleh public relation (PR). Tugas seorang public relation adalah sebagai penyampai pesan dan dapat langsung mensosialisasikan sebuah produk unggulan yang akan diperkenalkan. Disini terlihat bahwa kebanyakan produk dibeli karena berdasarkan rekomendasi personal approach seorang 
public relation, dan bukan karena didapat dari hasil iklan yang mendorong media agar menayangkan produk tersebut.

Pada dasarnya, antara jasa periklanan dan public relation digabung dengan menggunakan teknologi yang semakin canggih. Dengan demikian, periklanan yang pangsa pasarnya dapat menjangkau semua konsumen dapat saling mengisi dengan bantuan public relation yang bersifat menjangkau person to person. Selanjutnya, dalam masalah sebuah produk yang dengan merek dagang baru yang membutuhkan kepercayaan hanya dapat dilakukan oleh seorang public relation. Sebuah nama baru dari sebuah produk merupakan suatu liabilitas dalam program periklanan, namun hal ini adalah sebuah aset dalam public relation.

Hal yang tak kalah penting adalah masalah kreatifitas dalam dunia public relation. Kreatif memiliki arti 'orisinil', yang dalam public relation berarti ide kreatif yang dimasukkan dalam teknik public relation, khususnya untuk memperkuat ide yang sudah ada. Hal ini merupakan esensi mendasar dari konsep positioning. Hal penting lain adalah masalah "kepercayaan konsumen”. Pada dasarnya, konsumen jika tidak mengetahui sebuah produk atau kategori baru, mereka biasanya akan lebih percaya terhadap apa yang dibaca terkait produk yang akan dibeli, terlebih apabila informasi tersebut berasal dari sumber yang dapat dipercaya. Itulah sebabnya pembangunan merek melalui seorang public relation memiliki peran sangat strategis dan besar.

Pada umumnya, dalam mensosialisasikan sebuah produk, perusahaan lebih memiliki kecenderungan membelanjakan uang terlalu berlebihan untuk periklanan dan terlalu sedikit untuk public relation. Dan yang terakhir, pada hakikatnya sebuah periklanan memiliki masa depan yang dapat menjadi gemilang andai ia dapat menerima peran sejatinya dalam siklus hidup sebuah merek dari sebuah produk, yang telah dibangun dengan teknik-teknik public relation dan saling mengisi, yaitu sebuah merek dari sebuah produk akan membutuhkan periklanan untuk mempertahankan posisinya.

Di sisi lain, public relation sangat memerlukan untuk dapat bergerak menaiki tangga untuk permerekan (branding) sehingga public relation memiliki tanggung jawab dalam peran dan fungsi sejatinya dalam proses meraih pangsa pasar dan membangun branding image dalam sebuah merek dari sebuah produk yang akan dipasarkan. Beberapa merek yang sudah beredar di pasaran selama puluhan tahun, namun mungkin sama sekali belum pernah mmasuki benak prospek. Untuk yang menyangkut pemasaran, mereka inilah yang mana merek-merek baru yang membutuhkan public relation dalam jumlah besar sebelum mereka dapat berpaling ke periklanan untuk mendapatkan dukungan public relation terlebih dahulu, baru setelah itu periklanan akan digunakan sebagai satu kesatuan langkah dari teknik marketing yang seutuhnya.

\section{Membangun Jaringan Periklanan dan Public Relation Menggunakan Teknologi Baru}

Sebuah perubahan terjadi di bidang komunikasi. Beberapa pakar melihatnya sebagai "Revolusi Komunikasi”, dan beberapa menamakan sebagai "Zaman Baru Komunikasi”. Manusia sebagai makhluk sosial yang akan selalu mengadakan hubungan antara manusia dengan media komunikasi, dan memiliki tujuan membagi pengetahuan serta pengalamannya. Dalam perkembangan teknologi saat ini menunjukkan kemajuan yang sangat pesat seperti pada kenyataan keseharian di setiap kegiatan kehidupan tak terlepas dari keberadaan teknologi. Kehadiran teknologi telah memberikan implikasi, baik dari positif dan negatifnya yang cukup besar terhadap kehidupan.

Menurut Schramm (1988), perkembangan yang dinamakan revolusi komunikasi merupakan bagian dari serangkaian perubahan yang telah berlangsung dalam sejarah kehidupan manusia. 
Bila kembali pada definisi yang dikemukakan oleh Marshall Mcluhan, seorang guru besar dari Toronto University bahwa "The medium is the mass age". Menurut Mcluhan, media adalah era massa, yang memiliki arti bahwa saat ini kita hidup di era yang unik dalam sejarah peradaban manusia, yaitu era media massa. Terutama pada era elektronik seperti saat ini media pada hakikatnya telah mempengaruhi cara berpikir, merasakan, dan bahkan bertingkah laku. Saat ini terjadi revolusi masyarakat menjadi massa karena hadirnya media massa.

Mcluhan mendefinisikan sejarah kehidupan manusia ke dalam empat periode, yakni sebagai berikut. Pertama, The Tribal Age. Manusia hanya mengandalkan indera pendengaran dalam berkomunikasi. Komunikasi pada masa ini hanya berdasarkan narasi, dongeng, cerita, tuturan, dan sejenisnya. Kedua, The Age of Literacy: Sejak ditemukannya huruf dan alfabet, manusia berkomunikasi tidak lagi mengandalkan tuturan, tetapi lebih kepada tulisan. Ketiga, The Print Age. Semenjak ditemukannya mesin cetak menjadikan alfabet, semakin tersebar luas dan manusia berkreasi dalam mengembangkan cara berkomunikasi. Keempat, The Electronic Age. Ditandai dengan ditemukannya berbagai alat sebagai kemajuan teknologi komunikasi seperti telegrap, telepon, radio, film, televisi, VCR, mesin fax, komputer, dan internet. Manusia menjadi hidup di alam yang disebut "Global Village", misalnya media massa yang dapat berhubungan dengan yang lain tanpa batas negara.

Oleh sebab itu, dapat ditarik sebuah benang penghubung, yaitu media massa menurut kajian dari Mc Luhann bahwa manusia dapat berhubungan dengan yang lainnya tanpa batas negara akan ditunjang dari pendapat Daniel.H. Pink dengan yang dikatakannya sebagai era pada abad 20 dan 21 adalah era "Informasi dan Konseptual”. Hal ini memiliki dampak dan implikasi, baik dampak yang bersifat positif dan negatif, ketika persoalan perkembangan Teknologi Komunikasi dikaitkan dan dihubungkan dengan masalah sistem bekerjanya Periklanan dan public relation. Dalam hal ini, dunia dengan teknologi baru tak terlepas dari teknologi baru saat ini yang digunakan. Selanjutnya, untuk lebih dapat digambarkan bagaimana sebenarnya sebuah media elektronik dengan menggunakan bantuan internet dapat memfasilitasi jalannya dunia periklanan dan dunia public relation.

Pada akhir 1990-an terjadi internet booming yang telah menciptakan masalah yang cukup besar bagi banyak perusahaan dot.com pemula karena setiap individu terjun ke net, maka sebuah situs dapat menghasilkan cukup publisitas yang akan berdampak dalam menghasilkan publisitas bagi perusahaan sehingga namanya akan terkenal dan diakui keberadaannya. Dalam hal menjembatani antara fungsi media internet dapat saling mengisi dunia periklanan dan dunia public relation. Dalam mencermati bagaimana teknologi komunikasi yang semakin canggih telah banyak membantu di dunia periklanan dan dunia public relation, sebenarnya dalam kenyataannya internet sebagai fasilitator dan mediator dalam proses memperkenalkan sebuah jenis produk yang akan dipasarkan, sering menjadi bersaing dengan dunia public relation, dengan cara menggunakan periklanan online secara besarbesaran untuk menjadi terkenal, tanpa terlebih dahulu menggunakan jasa public relation ketika hendak membangun sebuah produk dan identitas perusahaan.

Selanjutnya dalam The Concept the spread of science and technology communication dikemukakan sebuah hubungan antara ilmu pengetahuan dan teknologi yang memberikan kontribusi besar di dalam dunia komunikasi, dunia periklanan, dan dunia public relation dengan sendirinya memiliki kaitan yang cukup signifikan. Dalam dunia periklanan dan public relation yang selalu hampir dipastikan memiliki hubungan yang erat dengan dunia komunikasi serta memiliki hubungan secara tak langsung dengan ilmu pengetahuan dan teknologi. Seorang agen periklanan dan agen public relation yang selalu bekerja untuk mengkomunikasikan setiap produk yang akan dipasarkan, sudah barang tentu sangat membutuhkan cara berkomunikasi dan mengirimkan komunikasi kepada para konsumen.

Dalam perkembangan dunia di era komunikasi yang sudah semakin canggih di mana penggunaan ilmu pengetahuan (science) dan teknologi menjadi bagian yang tak terpisahkan dalam 
kehidupan saat ini, begitu juga dengan dunia periklanan dan dunia public relation sumbangan ilmu pengetahuan dan teknologi memiliki dampak positif dan tentu juga ada dampak negatifnya. Dunia periklanan dan public relation telah diwarnai berbagai perubahan sejak munculnya teknologi, terutama teknologi komunikasi yang berupa internet.

Pada dasarnya, teknologi komunikasi telah menjadi alat bantu dalam peta perkembangan periklanan dan public relation, di mana fungsi dari keduanya tersebut adalah untuk kepentingan pemasaran sebuah produk yang memiliki tujuan menjangkau pasar seluas-luasnya. Dalam fungsi menjangkau pasar seluas-luasnya, maka penggunaan ilmu pengetahuan dan teknologi, di mana disini pilihannya adalah teknologi komunikasi, maka dengan menggunakan internet maksud dan tujuan kepada hasil untuk merangkul pasar sebesar-besarnya akan dengan mudah dicapai. Namun demikian untuk menggunakan teknologi komunikasi sebagai alat bantu pencapaian target marketing tentu saja memerlukan sebuah desain yang teliti dan perlu disiasati, guna mendapatkan hasil akhir yang maksimal. Perlu menjadi catatanm, dalam setiap usaha pasti ada dampak positif dan negatif sehingga benar-benar memerlukan sebuah persiapan ketika kita sudah akan memulai dengan sebuah desain baru dalam mencapai target pemasaran, baik pilihannya memakai iklan atau dengan cara menggunakan pilhan lewat public relation. Pembangunan sebuah merek yang akan diciptakan oleh para pencipta iklan dan public relation yang akan dibantu dengan adanya ilmu pengetahuan, teknologi, dan perkembangan teknologi, khususnya di bidang komunikasi akan menjadi peluang ketika hal ini diatur pengelolaan manajemennya agar dapat menjadi peluang membantu dalam membangun jalur sosialisasi pemasaran yang dapat ditangkap konsumen.

\section{Hubungan antara Ilmu Pengetahuan dan Teknologi Komunikasi}

Gambar 1 merupakan skema tindakan yang mengaktifkan komunikasi sains dan dampaknya. Skema memperlihatkan jika tingkat kepentingan umum, kesadaran, dan pemahaman dari sains dan teknologi disempurnakan, maka manusia dapat menikmati kehidupan yang lebih baik, yaitu negara akan lebih dimudahkan oleh sains dan teknologi.

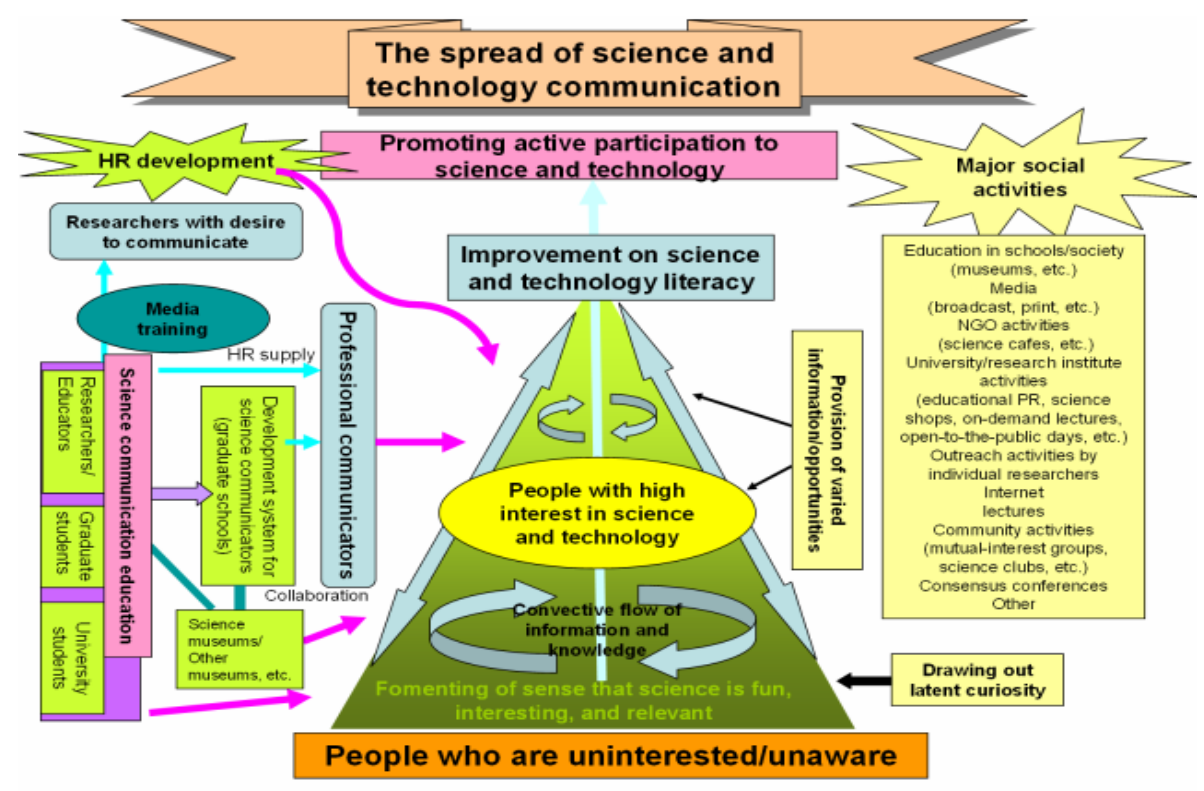

Gambar 1 Conceptual Figure of the Spread of Science and Technology Communication (sumber www.nistep.go.jp/nistep/about/thema/thema6-e.html) 


\section{Penggunaan Teknologi Komunikasi dalam Periklanan dan Public Relation}

Ketika teknologi komunikasi menjadi partner dalam dunia periklanan dan public relation, maka akan ada dua kemunngkinan, yakni akan menjadi partner yang membantu, atau sebaliknya akan memiliki kecenderungan penurunan dan tidak membantu sama sekali, sebagai contoh berikut. Pertama, contoh situs dot.com yang mengalami kegagalan. Kebangkrutan WingspanBank.com yang menurut data diluncurkan pada bulan Juni 1999 dengan gelombang periklanan koran, radio, televisi, dan internet. Layanan Bank adalah jasa yang melayani, menjual, dan menarik kepercayaan konsumen. Bank One Corporation kesulitan untuk mengakui bahwa situs WingspanBank.com miliknya yang dibanggakan ternyata terpuruk. Menurut laporan Wall Street Journal, bank internet ini hanya mampu beroperasi selama dua tahun. Namun, sebenarnya masih memiliki peluang untuk membangun satusatunya Bank Internet dengan biaya layanan lebih rendah dengan suku bunga tabungan yang lebih tinggi. Tetapi, hal ini tidak dapat dilakukan oleh kerja periklanan lewat online saja, melainkan harus dilakukan pendekatan melalui public relation. Kedua, contoh dot.com yang meraih sukses agar meraih sukses harus memiliki faktor penggugah motivasi yang berdampak positif terhadap keberhasilan publisitas positif, contohnya sebagai berikut: Amazon adalah sebuah toko buku internet yang bukan pertama karena yang pertama adalah Powells.com. Namun demikian, Amazon adalah yang pertama memasuki pikiran dan benak konsumen. Hal ini dilakukan dengan memberi tawaran diskon 30\%, dan ternyata memotivasi konsumen untuk mengunjungi situs ini dan benar-benar membeli buku; berikutnya adalah American Online. Ini merupakan salah satu provider jasa internet yang bukan pertama karena ISP adalah yang pertama. Namun, kenyataannya American Online (AOL) dengan bantuan dari public relation dan jasa periklanan pada 1 Desember 1996 berhasil menawarkan pelayanan jasa flat-rate yang menarik para konsumen untuk termotivasi dan menjadi pelanggan.

Contoh kasus tersebut memberikan gambaran bahwa ilmu pengetahuan dan teknologi dapat bekerja sama dengan baik ketika ilmu tersebut tepat digunakan. Hal ini memerlukan sebuah kajian analisis yang lebih mendalam tentang pencitraan sebuah produk yang akan ditayangkan dan agar dapat menjadi tak sekedar hiasan dan sekedar memiliki situs online.

Dapat disimpulkan bahwa pihak periklanan dan public relation dapat memanfaatkan berbagai situs untuk bekerja sama dalam meningkatkan cara menarik pasar. Semua ini bergantung cara dan rancangan yang matang dari para pembuat iklan dan public relation dalam menggunakan kesempatan, kemudahan, dan peluang untuk menghasilkan hasil yang maksimal dalam memasarkan produk unggulan yang akan dipasarkan.

\section{SIMPULAN}

Untuk membangun sebuah image dan branding, maka diperlukan sebuah konsep yang menggabungkan periklanan, public relation, dan teknologi karena masing-masing mempunyai kielebihan dan kekurangan. Pemahaman sifat dasar manusia sebagai target konsumen atau pelanggan diperlukan. Para pembuat pesan periklanan dan jasa public relation perlu memahami sifat kerja dari teknologi komunikasi agar sebuah pesan penawaran yang akan dilemparkan ke para konsumen menjadi tidak sia-sia.

Faktor kreativitas memegang peranan sangat penting, yaitu bagaimana seorang pembuat jasa iklan dan jasa public relation dapat bekerja sama dalam menggunakan teknologi komunikasi sebagai alat bantu penyampaian pesan kepada konsumen agar dapat menarik bagi mereka. Nilai lebih dari periklanan adalah harus cerdas, menarik, provokatif, menghibur, menghebohkan, dramatis, dan dapat diproduksi dengan baik. Demikian juga sifat public relation yang merupakan seni mendapatkan dan memanfaatkan kepercayaaan konsumen dengan cara yang kreatif, persuasif, dan komunikatif. Pada 
akhirnya, jasa teknologi komunikasi yang semakin pesat dan canggih dapat menjadi peluang baru dan inovatif yang dapat menjembatani antara periklanan dan public relation. Intinya adalah bagaimana "membangun merek" dengan kemudahan dan kecanggihan teknologi.

\section{DAFTAR PUSTAKA}

Gagliardi, G. (1999). Sun Tzu's, the art of war plus the art of sales, strategy for salespeople, Clearbridge Publishing.

Kartajaya, H. (2002). On marketing, Jakarta: PT Gramedia.

Pink, D. H. (2002). A whole new mind, berpindah dari zaman informasi menuju zaman konseptual, edisi Indonesia, PT Abdi TANDUR. Retrieved from http://www.nistep.go.jp/nistep/about/thema/thema6-e.html.

Ries, A., and Ries, L. (2003). The fall of advertising and the rise of PR, Jakarta: PT Gramedia. 